PESHAWAR JOURNAL OF PSYCHOLOGY AND BEHAVIORAL SCIENCES, 2018, VOL. 4, NO. 2, 237-246

\title{
Self-Concept and Self-Esteem among Adults
}

\author{
Aqsa Batool', Amna Ajmal', \\ Shumaila Abid ${ }^{3}$ \\ Bahauddin Zakariya University, Multan \\ and
}

\section{Hina Iqbal}

Islamia College Peshawar

The study aimed at the investigating of the association between self-concept and self-esteem among university students. The sample comprised of 244 university students randomly selected, that included 72 male and 173 female students of Bahauddin Zakariya University, Multan. Besides demographic information sheet two scales were used for measuring self-esteem Rosenberg's Self- esteems scale (Rosenberg, 1965) was used and self-concept was measured through the multiple self concept scale by Bruce A. Bracken. The data was collected in form of group, because these scales can be administered in group. The results of the study revealed slightly significant positive correlation between self-concept and self esteem among university students. It was further revealed that there was significant difference on scores of self-concept however there was no significant difference between the scores of self esteem. It therefore concluded that self-concept and self-esteem have positive relationship.Self concept may be associated to gender.

Keywords: self-concept, self-esteem, adults, gender

Self-concept and Self-esteem are ironic elements of the personality. These two components always travel on parallel road in our lives. Self-

\footnotetext{
${ }^{1}$ Psychologist, Government Institute for Slow Learner, Layyah, Special Education Department, Punjab

${ }^{2}$ Lecturer, Department of Applied Psychology, Bahauddin Zakariya University, Multan

${ }^{3}$ Lecturer, Department of Applied Psychology, Bahauddin Zakariya University, Multan

ISSN 2415-6779 EISSN 2518-4474

https://doi.org/10.32879/picp.2018.4.2.237

www.pjpbsicp.com
} 
concept how do we develop a specific perception about ourselves. Selfesteem is something that how we evaluate ourselves.

Self concept and self esteem development commence since childhood. It is a continuous process that continues to develop across life span. It is inevitable to have a positive self concept and elated self esteem for a satisfied and prosperous adulthood. Although there is a congruent bond between positive self concept and self esteem, if Self concept declines then Self esteem fluctuates. Adult students in university frequently compare each other in academic, social, and cultural context and evaluate themselves. Adults sometimes decline and uplift their self concept and self esteem in comparison with other adults in their social network in university.

Liv Berit and Stefan Elmer (2017) made a comprehensive study on the relationship of current scientific knowledge with self concept and self esteem among young adolescent with visual impairment. The both researcher applied cross sectional design in their work. They inferred that vision loss and age was the defining feature to influence self esteem among young adults. In order to uplift their self concept and self esteem, they stressed upon secure parenting style, autonomy in mobility and social support are important.

Another work conducted on medium level positive self concept on academic achievement of students. She argued in the light of her metaanalysis findings that self concept had a medium positive effect on academic achievement of students. (Sabiha Dulay, 2017).

The critical study evaluated by Francesca Scalas and Herbert w. Marsh (2017) on the music self concept determining self esteem among students at secondary level. Using the application of models: individual and normative group, they performed their work. They took a sample of 512 junior high students (11-16 years old) for their studies. But they argued their inferences were supported by individual model rather than normative model. Besides these findings, they analyzed students 'musical performance has significant effect on self esteem.

The other comparative study on urban and rural young students conducted byDr. Rekha Srivastava, and Dr. Shobhna Joshi (2014) confronted a multiple different problems and challenges during their study of positive self concept and self esteem. They conducted their work on a sample of 400 students from urban and rule boys $(n=200)$ and girls $(n=200)$ in high and low faculty schools of India. The inculcations of the conducted quantitative study manifested that positive correlation exists between 
academic self concept and self esteem among urban and rural girls and boys in high and low faculty school.

The Pakistani researchers conducted their work on secondary school students in Punjab, Pakistan. A sample of 396 students was taken to evaluate the interconnected self concept and self esteem with self identity. Rosenberg Self-Esteem Scale (RSES) with translated version was applied to urban and rural student, and science and arts students. The findings of independent $t$ test of the study showed urban and students have more self esteem than rural and arts students. In addition, factor analysis of independent $t$ test depicted that boys have higher self esteem than girls. (Muhammad Faisal Farid and Mumtaz Akhtar, 2013).

The research was conducted in the United States and London by Booth and Gerad in 2011. They accomplished their research in adolescents on self esteem to evaluate gender difference in having self esteem in the areas of London and US. They conferred that boys have more self esteem as compared to girls. They also highlighted that girls have poor self esteem in Canadian schools than boys.

A discretional work was done on various measures of self and its relationship. Their study entailed about specificity of self concept ties to academic achievement in school. They further argued that general self concept is not related to academic activity, but specific measures of self depict consolidated relationship to academic success in content knowledge. (Swann, Chang-Schneider, and Mc Clarty, 2007).

Evaluating the preceding studies, it was unveiled that there are limited studies on relationship between self concept and self esteem among adults. It is concluded that the antecedent studies focused on finding the relationship between self concept and academic achievement; some studies were proposed to evaluate effect of musical self concept on self esteem among young boys and girls at school level. Hence, restricted work on the effect of self concept on self esteem among university students prompted to conduct the present study among adults.

The adults at this age have a sense of identity. So, their sense of self concept has deep roots in developing self esteem. Self concept and self esteem are interchangeably used in the life of adults. So, self concept and self esteem are the core components of personality development and academic achievement among adults of university students. The university environment has a combination of different social, academic and cultural factors that shape the self concept of the adults. These factors may be influence the self concept and self esteem in positive or negative ways. In

PESHAWAR JOURNAL OF PSYCHOLOGY AND BEHAVIORAL SCIENCES, 2018, VOL. 4, NO. 1, 237-246 
addition to this, gender disparity has always been kept under careful consideration in Pakistan. The concept of self concept and self esteem develop differentially in boys and girls of the university. To cut the long story short, self concept and self esteem needs to be evaluated among university students.

\section{Objectives of study}

- To investigate the relationship between self-concept and self esteem among adults

- To study the gender difference between adult males and females on self esteem.

- To study the gender difference between adult males and females on self esteem.

\section{Hypotheses}

- There will be positive relation between self esteem and self-concept among adults

- There will be gender difference on the scores of self esteem among adults

- There will be gender difference on the scores of self concept among adults

\section{Sample}

\section{Method}

A Sample of 244 adults (male $=71$, female173) was extracted from Bahauddin Zakariya University, Multan. The sample comprised of undergraduate and postgraduate students. All adults were selected randomly from natural and social science departments of Bahauddin Zakariya University, Multan. The socioeconomic status of selected sample of male and female was almost similar. The minimum age of the participants was 18 years, who were undergraduate students and the maximum age was 25 that were postgraduate students. The sample was taken from department of sociology, psychology, linguistics, gender studies, and public administration. From the natural sciences, sample was taken from the department of chemistry, physics, statistics, biology and pharmacy.

\section{Instruments}

PESHAWAR JOURNAL OF PSYCHOLOGY AND BEHAVIORAL SCIENCES, 2018, VOL. 4, NO. 2, 237-246 
The Rosenberg Self-Esteem Scale devised by Rosenberg (1965), an evaluative parameter of individual self esteem. So, a four point Likert scale consisting 10 items was used in the study. The scores on scale range from 10 to 30; high score between 15 and 25 demonstrates high self esteem and low score below 15 describes low self esteem. The RSE has criterion validity 0.55 and test retest reliability ranges from 0.82 to 0.85 . According to Rosenberg, the items on the scale are equally positive and negative. The ten items on the scale are used to assess self worth of a person critically. On the other hand, for the inquiry of self concept, a multidimensional self concept scale engineered by Revised Janis and Field Scale was used. The instrument was the Fleming Courteny revision of Janis-Field Scale, 1984. The reliability of the instrument was 0.91 and split half reliability was 0.83 . multidimensional self concept scale entailed 36 items and a seven point Likert scale. The scoring ranges from 1 that describes very often to 7 almost never. This scale explored global self esteem and self regard, physical appearance and social confidence. Some items in the scale are reversely scored. High scores lead to high self esteem.

\section{Procedure}

For the purpose of data collection, formal permission was sought from the heads of the department concerned and the students were briefed about objectives of the study by taking informed consent. Students were assured of the confidentiality of their responses as a top priority. Questionnaires were distributed in the same sequence and data was collected in the form of group.

\section{Results}

To inculcate the significant relationship between self concept and self esteem the coefficient correlation was used. On demographic basis, $t-$ test was used to investigate the differences of variable on gender difference

Table 1

Mean, Standard Deviation and Correlation between Self Concept and Self Esteem among Adults $(N=244)$

\begin{tabular}{cccccc}
\hline & & 1 & 2 & Mean & SD \\
\hline 1 & Self-Concept & & - & 134.93 & 23.56 \\
2 & Self-Esteem & - & $.14^{*}$ & 21.51 & 3.05 \\
\hline
\end{tabular}

PESHAWAR JOURNAL OF PSYCHOLOGY AND BEHAVIORAL SCIENCES, 2018, VOL. 4, NO. 1, 237-246 
Note: $* p<.05 \& * * p<.01$

Table 1 shows significant positive correlation between scores of self concept and self esteem. Correlation value .14 that is significant at $p<.02$.

Table 2

Mean, Standard Deviation, $t$-Value of Measure of Self Concept among Male and Female Adults $(N=244)$

\begin{tabular}{lcccccccc} 
& & & & & & \multicolumn{2}{c}{$95 \% C I$} & Cohen's \\
\cline { 6 - 7 } Gender & $\mathrm{N}$ & $\mathrm{M}$ & $\mathrm{SD}$ & $t(242)$ & $p$ & $L L$ & $U L$ & $d$ \\
\hline Male & 71 & 126.90 & 26.29 & -3.48 & .001 & -17.7. & -4.92 & .47 \\
Female & 173 & 138.22 & 21.58 & & & & & \\
\hline
\end{tabular}

Table 2 shows the mean difference of self-esteem on the basis of gender. males, $(M=126.90, S D=26.29)$ and female adults $(M=138.22$, $\mathrm{SD}=21.58),(\mathrm{t}=-3.48, \mathrm{p}<.001)$, indicates that there is a highly significant difference on the scores of self-concept between males and females.

Table3

Mean, Standard Deviation, $t$-Value of Measure of Self Esteem among Male and Female Adults $(N=244)$

\begin{tabular}{lccccccccc}
\hline & & & & & & \multicolumn{3}{c}{$95 \% C I$} & Cohen's \\
\cline { 7 - 8 } Gender & $\mathrm{N}$ & $\mathrm{M}$ & $\mathrm{SD}$ & $\mathrm{t}(242)$ & $\mathrm{P}$ & $L L$ & $U L$ & $d$ \\
\hline Male & 71 & 21.25 & 3.54 & -.84 & .13 & -1.21 & .48 & .11 \\
Female & 173 & 21.61 & 2.83 & & & & & \\
\hline
\end{tabular}

Table 3 shows the mean difference of self esteem on the basis of gender. Males, $(\mathrm{M}=21.25, \mathrm{SD}=3.54)$ and Female adults $(\mathrm{M}=21.61$, $\mathrm{SD}=2.83),(\mathrm{t}=-.83, \mathrm{p}>.05)$, indicates that there is no significant difference on the scores of self-esteem between males and females.

\section{Discussion}

The present study explored the effect of self-concept on self-esteem among adults. The multiple self-concept scale and Rosenberg self-esteem 
scale was used to measure the influence of self concept on self-esteem among adults. Statistical analysis depicted that self-concept is positively correlated with self-esteem among adults.

Coefficient correlation inferences evinced that there was positive correlation between self concept and self esteem with the value of 1 . Therefore, these research findings proved the first hypothesis of this study. Franken (1994) theory supported the first hypothesis in that adults having a good self-esteem definitely have differentiated self-concept. Carl Rogers (1959) theory of self-concept backed up the second hypothesis that there was a significant relationship between self-concept and self-esteem. Apart from theoretical backup, previous researches' findings supported the current inferences. The study also supported by preceding researches that the adults who have sense of positive self-concept scores high on self-esteem scale. (Baumeister, Campbell, Krueger \& Vohs, 2003). The other evidences witnessed about consolidation of first hypothesis was that positive selfconcept prompts positive and high self-esteem. (Farmer, 2001). Yu Wei Chu (2002) also argued that self-esteem was positively correlated with domain specific self-concept.

Another outcome of study hold up that "inculcated the significant relationship and positive correlation between self-concept and self-esteem among adolescents" supported the first hypothesis of the study. (Dr .Rekha Srivastava and Dr Joshi, 2014). t-test was performed to consolidate the hypothesis of the differential effect of self-esteem between male and female. $t$ test deductions claimed that there was no significant difference on scores of self-esteem between males and females. The other analysts described in their factor analysis of independent $t$ test depicted that boys have higher selfesteem than girls. (Faisal Farid \& Mumtaz Akhtar, 2013).

The significant results of gender difference were also in consonant with the study conducted in US and England. They conferred that boys have more self-esteem as compared to girls. They also highlighted that girls have poor self-esteem in Canadian schools than boys. (Booth and Gerad, 2011).

\section{Conclusion}

In the light of numerical inculcations, theoretical framework, and a vast query of subsequent studies, the fact deciphered that self-concept has significant effect on self-esteem among students. The significant inferences

were also in line with antecedent studies. The study has thrown light upon co relational ties between self-concept and self-esteem and it means that boosting self-concept may boon self-esteem among adults.

PESHAWAR JOURNAL OF PSYCHOLOGY AND BEHAVIORAL SCIENCES, 2018, VOL. 4, NO. 1, 237-246 
Moreover, there was defining disparity of self-esteem between males and females. In the context of gender differences in having selfesteem, facts about male dominant society could be a defining up lifter of self-esteem among male adults. So, that was the reason, male adults' posses' higher self-esteem.

\section{Limitations}

The sample was taken only from Multan, so there results cannot be generalized to population of all other countries. Sampling techniques was not the best representative of sample taken. Sample was limited to University students. The study conducted was among adults and didn't include young adults, middle adulthood and late adulthood. The study has not included other demographic variables like race, culture, class disparity and ethnic factors. The other hidden factors: parental attachment, social and peer acceptance, academic success and failure, career development was not considered in the study.

\section{Suggestions}

So, sample can be taken from schools, colleges and other universities by future analysts. The students can expand their study of effect of self-concept on self-esteem among teenagers and middle and late adulthood. Social and moral support, academic progress, career planning, no doubt impact on blossoming of self-esteem of an adult. So, students can consider these factors in their studies. The many other demographic contents like culture, family background, and different development span of the people can be evaluated in the light of self-concept and self-esteem development.

In addition to this topic 'the impact of self-concept on self-esteem', there are many other factors such as; family influences, physical selfconcept, academic and professional self-concept and peer effects on developing self-concept could be considered by subsequent researchers. It would, axiomatically, assist the people in self-awareness and self-efficacy. The teachers, educational institutions, organizations and national welfare agencies should promote pragmatic actions to induce education of selfconcept; self-awareness thought patterns and self-esteem uplifting guidelines in the adults for the better and prosperous life.

Implications of the study:

The major hallmark of the study highlighted the different features of self-concept and self-esteem to the adults. During the phase of study, the 
adults recognized their self-concept and self-esteem comprehensively. The empirical evidences of the study opened the new ways in the theory and research era of personality development. To cut the long story short, the study revealed the fact that both variables: self-concept and self-esteem are in strong bond and directly proportional to each other in the human life sphere. Besides, facts and figures about conception of self-esteem on gender basis disclosed that ascending and descending level of self-esteem among boys and girls have different sources in the university atmosphere.

\section{References}

Booth M.Z. and J. M. Gerad, 2011. Self-esteem and academic achievement: a comparative study of adolescent students in England and the US Compare: A Journal of Comparative and International Education, 120.

Baumeister, R.F., J.D. Campbell, J.J.Krueger and K.D. Vohs, 2003. Does high self-esteem cause better performance, interpersonal success, happiness or healthier lifestyles? Psychological Science in the Public Interest, 4(1):1-44.

Scalas, L. F., Marsh, H. W., Vispoel, W., Morin, A. J. S., \& Wen, Z. (2017). Music self-concept and self-esteem formation in adolescence: A comparison between individual and normative models of importance within a latent framework. Psychology of Music. Advance online publication.

Dr.Rekha Srivastava and Dr. Shobhna Joshi (2014); Relationship between Self-concept and Self-esteem in adolescents. Int. J. of Adv. Res. 2 (2). 0 (ISSN 2320-5407). www.journalijar.com

Dulay S. (2017) the Effect of Self-concept on Student Achievement. In: Karadag E. (eds) The Factors Effecting Student Achievement. Springer, Cham

Faisal Farid and Mumtaz Akhtar (2013), Self-esteem of secondary school students in Pakistan. Middle East Journal of Scientific Research 14(10):1325-1330, 2013.

Fleming J.S. and Courteny, B.E. (1984). The dimensionality of self-esteem: II. Hierarchical facet model for revised measurement scales. Journal of personality and social psychology, 46, 404-421.

Franks, D. D., \& Marolla, J. (1976). Efficacious action and social approval as interacting dimensions of self-esteem: A tentative formulation through construct validation. Social Psychology Quarterly, 39, 324341 .

PESHAWAR JOURNAL OF PSYCHOLOGY AND BEHAVIORAL SCIENCES, 2018, VOL. 4, NO. 1, 237-246 
Josephs, R.A., Markus, H.R., \& R.W. (1992) Gender and Self-esteem. Journal of personality and social psychology, 63,391-402

LivBerit Augestad and Stefan Elmer (2017)Self-concept and self-esteem among children and young adults with visual impairment: A systematic review

McLeod, S. A. (2014, Feb 05). Carl Rogers. Retrieved from https://www.simplypsychology.org/carl-rogers.html

Rosenberg, M. (1965). Society and the adolescent self-image. Princeton, NJ: Princeton University Press

Yu Wei Chi 2001. The relationship between domain specific self-concept and global self-esteem among adolescents in Taiwan. Bulletin of educational psychology, 33,103-123 